\title{
Assessment of Plutonium Inventory Management in the French Nuclear Fleet with the Fuel Cycle Simulator CLASS
}

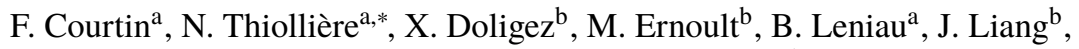 \\ B. Mouginot ${ }^{\mathrm{c}}$, A.-A. Zakari-Issoufou ${ }^{\mathrm{b}}$ \\ ${ }^{a}$ Subatech, IMT Atlantique - IN2P3/CNRS - Université, Nantes, F-44307, France \\ ${ }^{b}$ IJC Lab, CNRS-IN2P3/Univ. Paris Sud, France \\ ${ }^{c}$ Univ. of Wisconsin Madison, Department of Nuclear Engineering and Engineering Physics, Madison, WI, \\ United States
}

\begin{abstract}
The ASTRID French project aimed at designing, building and operating a sodium fast reactor cooled with liquid sodium. One of the goals of the project was to demonstrate the feasibility of the plutonium multi-recycling in a fast spectrum. Commissariat à l'énergie atomique et aux énergies alternatives (CEA - Atomic \& Alternative Energies Commission) has recently announced the abandon of the project which involves that no sodium fast reactor project is planned in France. As a consequence, there is a real interest in assessing technical feasibility for alternative plutonium management. In this work, the plutonium multi-recycling in PWR is assessed from fuel cycle simulations performed with the library CLASS developed by CNRS/IN2P3. The technical conditions for plutonium incineration and stabilization are investigated. It is shown that plutonium can be stabilized with $30 \%$ of PWR using multi-reprocessed plutonium in MOX fuel, the rest being composed by PWR loaded with UOX. The transuranic (plutonium and minor actinides) stabilization involves a plutonium incineration. For this reason, around $50 \%$ of PWR using multi-reprocessed plutonium is required and the nuclear power has to decrease. In this paper, the methodology and the output analysis are described in detail.
\end{abstract}

Keywords: Fuel Cycle Simulation, Plutonium reprocessing, Pressurized Water Reactors, Sensitivity analysis

\footnotetext{
* Corresponding author

Email address: nicolas. thiolliere@subatech.in2p3.fr (N. Thiollière )
} 


\section{Contents}

1 Introduction 4

2 Plutonium multi-recycling in PWR 6

2.1 Physics of Pu multi-recycling in PWR . . . . . . . . . . . 6

${ }_{5} \quad 2.2$ Description and simulation of MOX on enriched uranium support concept 7

3 Scenario study description $\quad 8$

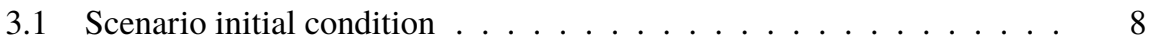

3.2 Scenario framework . . . . . . . . . . . . . . . 9

3.3 Input variable space $\ldots \ldots \ldots \ldots \ldots \ldots \ldots \ldots$

${ }_{10} \quad 3.4$ Design Of Experiments $\ldots \ldots \ldots \ldots \ldots$

3.5 Output and nomenclature $\ldots \ldots \ldots \ldots \ldots$

4 Scenario Output analysis $\quad 14$

4.1 Total power, energy and inventory . . . . . . . . . . . . . 15

4.2 Sobol' indices analyse . . . . . . . . . . . . . . . . 15

15

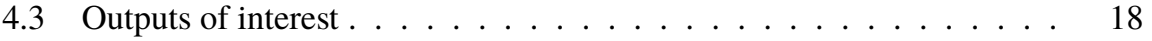

5 Plutonium stabilization $\quad 19$

5.1 stabilization criteria . . . . . . . . . . . . . . . 20

5.2 Input variables distributions $\ldots \ldots \ldots \ldots \ldots \ldots \ldots$

5.3 Minor Actinides production . . . . . . . . . . . . . . . 23

${ }_{20}^{20} \quad 5.4$ Plutonium stabilization summary . . . . . . . . . . . . . . . . . 24

6 Transuranic stabilization $\quad 25$

6.1 Stabilization criteria . . . . . . . . . . . . . . . . 26

6.2 Input variables distribution $\ldots \ldots \ldots \ldots \ldots \ldots$

6.3 Transuranic stabilization summary $\ldots \ldots \ldots \ldots \ldots$

$\begin{array}{llll}25 & 7 & \text { Conclusions } & 31\end{array}$ 


\section{Acronyms}

APA Advanced Plutonium Assembly. 6

BoC Beginning of Cycle. 18, 19, 27

BU Burn up. 8, 10, 11, 13, 17, 18, 23, 27

CORAIL Combustible Recyclage A Ilot. 6

DOE Design Of Experiment. 8, 13, 14

EoS End of Scenario. 14-16, 18-20, 23-25

FCS Fuel Cycle Simulator. 10

FP Fission Products. 4, 5, 10

${ }_{35} \quad$ FR Fast Reactor. 4, 5

HN Heavy Nuclides. 10

MA Minor Actinides. 4, 5, 9, 10, 14-16, 18, 23-27, 29, 30

MOX Mixed OXide. 4, 5, 8-11, 31

MOX-EUS Mixed OXide on Enriched Uranium Support. 6, 7, 9-14, 16-19, 21-27,

PWR Pressurized Water Reactor. 4-8, 10-14, 17-19, 21-27, 30-32

SFR Sodium Fast Reactor. 4, 5

UOX Uranium OXide. 4, 8-11, 13, 17, 18, 21-24, 26, 27 


\section{Introduction}

45 Several countries are engaged in an energy transition in order to reduce greenhouse gases generated by fossil-fuel consumption. France is part of them and has definitely adopted the energy and climate bill in 2019 [1]. Main targets are mentioned below :

- Achieve zero net emissions and carbon neutrality by 2050

- $40 \%$ reduction of fossil fuel consumption by 2030 in comparison with 1990 level 60's [4] with the goal of closing the fuel cycle. In France at that time, the context of uncertainty related to uranium availability required a more efficient utilization of the resource. In order to study this approach, three Sodium Fast Reactor (SFR)s have been designed, built and operated in France: Rapsodie [5], Phoenix [6] and Superphenix [7]. Reprocessing Plant) and a plutonium-based fuel fabrication plant (Melox recycling plant, located in Marcoule) were built to produce MOX fuel used in PWR, intermediate steps before the nuclear fuel cycle closure. In this French very specific framework, the plutonium is a resource that is used to operate PWR and that may be used later to Products (FP). 
This long-term vision has faced many oppositions and SFR future after Superphenix final shutdown in 1997 was not clear. On 5 January 2006, the French president J. Chirac has announced the commissioning of a SFR demonstrator for 2020. This statement has been reinforced by the 2006 program act on the sustainable management of radioactive materials and wastes [8]. This has marked the beginning of the ASTRID program [9]. In this new context, the interest for SFR was also reinforced by their ability to transmute MA [10]. France's Commissariat à l'énergie atomique et aux énergies alternatives (CEA - Atomic \& Alternative Energies Commission) has recently announced the abandon of the project [11]. Furthermore, the French Multi-annual Energy Programme (PPE) for the period 2019 to 2028 raises the construction of a SFR demonstrator at the end of the 21 st century.

In this new context, the plutonium status could be redefined, from recoverable material to high-level waste. In 1991, the Law no. 91-1381 of 30 December 1991, 85 known as the âĂIJBatailleâĂİ Law, defined three study axes for the high-level waste (MA and FP) [12]:

- Separation and Transmutation of long-life radioactive elements,

- Options for deep geological disposal,

- Packaging and long-term surface storage.

According to French Environment Code, radioactive waste is a radioactive substance for which no further use is planned or envisaged. This definition clearly excludes plutonium from nuclear waste categories since plutonium is currently used in PWR as MOX fuel and since plutonium incineration in SFR was planned. Plutonium inventory is increasing and the stockpiled mass in the current French fuel cycle is around 350 95 tons [13].

Without any FR project, the plutonium reprocessing interest is not clear since gains, in terms of uranium resource or plutonium incineration, are relatively limited. In those conditions, there is a real interest in assessing technical feasibility for alternative plutonium management. This paper aims to study the plutonium multi-recycling in PWR from fuel cycle simulations with the code CLASS [14]. The technical conditions 
for plutonium incineration and stabilization will be investigated. Tools and methodology will be presented. Outputs analysis will lead to fuel cycle parameters that fit with those objectives.

\section{Plutonium multi-recycling in PWR}

\subsection{Physics of Pu multi-recycling in PWR}

Plutonium multi-recycling in PWR is a technological challenge, mainly because of safety issues. Plutonium irradiation in a thermal spectrum induces a relative decrease of odd fissile isotopes $\left({ }^{239} \mathrm{Pu}\right.$ and $\left.{ }^{241} \mathrm{Pu}\right)$ compared to even isotopes $\left({ }^{238} \mathrm{Pu},{ }^{240} \mathrm{Pu}\right.$ and ${ }^{242} \mathrm{Pu}$ ). As a consequence, the plutonium fraction in the fresh fuel needed to reach criticality during a reactor cycle increases. Nevertheless, increasing the plutonium fraction may lead to a deterioration of the void coefficient. In practice, these maximum calculated contents vary from $12 \%$ to $15 \%$ according to the plutonium isotopic composition $[15,16,17]$.

Innovative designs have been studied in order to overcome those issues [18]. Some relevant and advanced concepts are based on uranium and plutonium elements and are listed below:

- Mixed OXide on Enriched Uranium Support (MOX-EUS) also called MIX concept,

- Combustible Recyclage A Ilot (CORAIL),

- Advanced Plutonium Assembly (APA),

- DUPLEX,

- REMIX technology.

Those concepts are based on the use of ${ }^{235} \mathrm{U}$ to compensate for the lack of reactivity that results from the constraint on maximal plutonium fraction imposed in fresh fuel. A comparative study of those assembly concepts can be found on [19, 20]. In Russia, an innovating fuel fabrication technology called REMIX-technology aims to build a fuel 
made from mixtures of uranium and plutonium isotopes blended with enriched natural uranium [21, 22]. A recent work presents characteristics of REMIX fuel assembly [23].

\subsection{Description and simulation of MOX on enriched uranium support concept}

In the framework of this work, the MOX-EUS fuel has been investigated because of the concept simplicity and its high plutonium incineration capacity. The MOX-EUS concept is a standard PWR assembly composed by 264 homogeneous pins of plutonium and uranium mix.

Reactor models have been built and integrated in CLASS for PWR fueled with MOXEUS from Monte-Carlo assembly calculations. A databank composed of 1000 PWRs infinite assembly (see Figure 1 for a view of the assembly section) depletion calculations performed using the software MURE (MCNP Utility for Reactor Evolution) [24] based on the transport code MCNP (Monte-Carlo N Particle) [25].

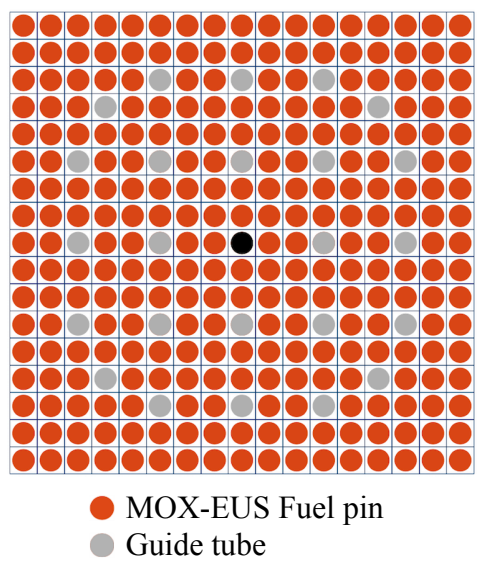

Figure 1: Evolution of the effective thermal power of the simulated French nuclear fleet (black, left vertical axis). Evolution of the plutonium (green, right vertical axis) and minor actinides mass (dotted line, green, right vertical axis).

Neural networks are trained to reproduce neutronic outputs with an excellent accuracy. Validated neural networks are used to build the fresh fuel and to calculate the fuel evolution during irradiation. This preliminary work has been fully described in [26]. 


\section{Scenario study description}

In this section, the scenario Design Of Experiment (DOE) is presented. All the fuel cycle simulations performed in this work are done with the code CLASS (Core Library for Advanced Scenarios Simulations) [13]. The precise definition of the initial time for the simulations is also described.

\subsection{Scenario initial condition}

A precise simulation of the French nuclear fleet has been performed, from the beginning of the nuclear program up to 2015 which is the starting point of scenario [27]. In order to have a precise simulation, input data (reactor Burn up (BU), load factors, cooling time, etc.) need to be robust and reliable. Due to sensitivity of this kind of information, collecting quality data may be complex. As a consequence, an important literature review has been performed in order to extract, compare and sort available and public information. References used in the framework of this work to reconstruct the French nuclear history are specified in the annex B of [27].

The French nuclear fuel cycle simulation takes into account 58 PWRs. These PWRs are classified according to their nominal thermal power $\mathrm{P}_{\text {th }}$ and heavy nuclides mass $\mathrm{M}_{\mathrm{HN}}$ in the core into different categories called series:

- 34 PWRs $900\left(\mathrm{P}_{\mathrm{th}}=2.8 \mathrm{GW}_{\mathrm{th}}, \mathrm{M}_{\mathrm{HN}}=72.5\right.$ tons $)$

- 20 PWRs $1300\left(\mathrm{P}_{\mathrm{th}}=3.8 \mathrm{GW}_{\mathrm{th}}, \mathrm{M}_{\mathrm{HN}}=104\right.$ tons $)$

- 4 PWRs $1450\left(\mathrm{P}_{\text {th }}=4.3 \mathrm{GW}_{\text {th }}, \mathrm{M}_{\mathrm{HN}}=110\right.$ tons $)$

In 2015, 22 PWRs 900 are loaded with around 30\% of MOX fuel since other reactors are loaded with UOX fuel. Several industrial fuel management strategies characterized by a different $\mathrm{BU}$, fissile enrichment or fuel loading plan are used. A reactor can also switch from one management to another during its lifetime. Reactors fuel discharge $\mathrm{BU}$ or industrial fuel management change dates extracted from public literature vary from one source to another. Reference data used to reconstruct the French nuclear fleet are then based on average of available reliable data. 
Reactors load factors are calculated from the PRIS (Power Reactor Information System) database [28]. Annual load factors per reactor are summarized through an averaged value that is used for all the reactor lifetime. The thermal power used in the simulation, called effective thermal power, is then the nominal thermal power multiplied by the averaged load factor. The Figure 2 shows the effective simulated thermal power and the plutonium and MA total mass evolution from the beginning of the French nuclear program up to 2015. Spent fuel and waste inventories computed from this very detailed simulation are used as the initial conditions for scenarios.

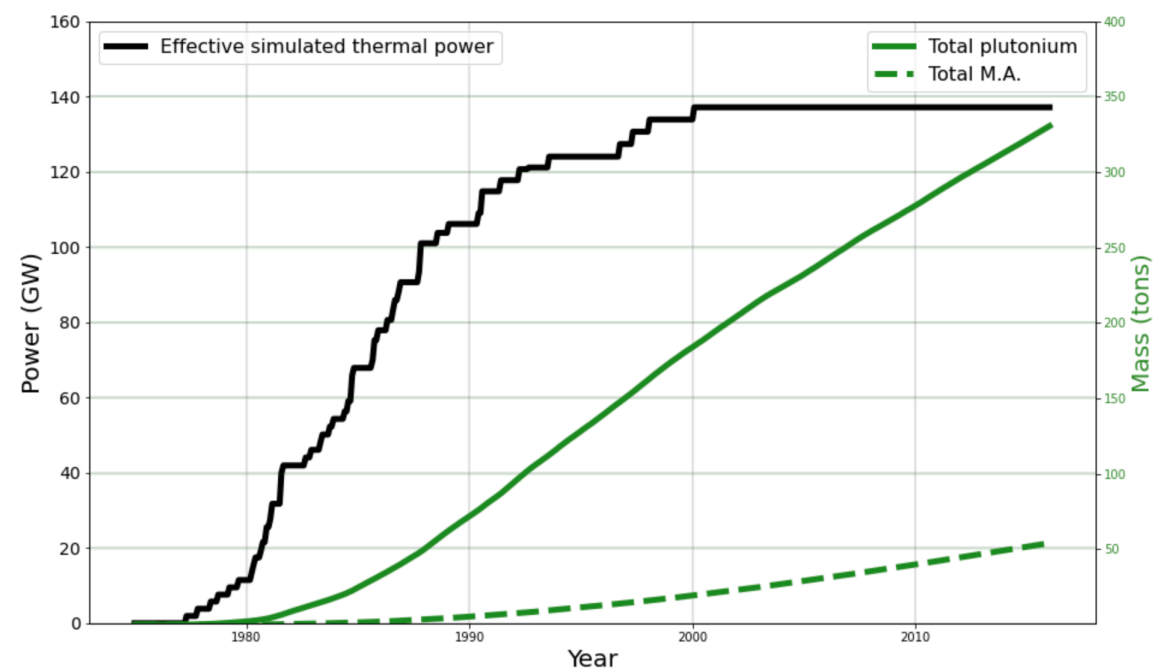

Figure 2: Evolution of the effective thermal power of the simulated French nuclear fleet (black, left vertical axis). Evolution of the plutonium (green, right vertical axis) and minor actinides mass (dotted line, green, right axis).

\subsection{Scenario framework}

In this work, a large sampling methodology on input parameters has been performed. In order to simulate a high number of trajectories, macro reactor approach has been used. Each reactor are combined and gathered into a unique reactor by type of fuel in the problem: UOX, MOX and MOX-EUS. Reactors parameters evolution can be treated as quasi-continuous. The annual power is modified from the fuel mass update by considering a constant specific power. This approach highly reduces the complexity 
of the simulation, the size of outputs and the simulation time. The viability of this important approximation has been validated and discussed in [27].

The scenario representation is shown on the Figure 3. The fleet is composed of two macro PWRs fueled with UOX (green facilities) and MOX (blue facilities). The transition toward the plutonium multi-reprocessing strategy consists in replacing the MOX component by the MOX-EUS stratum (red facilities). The fuel cycle starts with an infinite stock of natural uranium $U_{\text {nat }}$ used to build enriched Uranium $U_{\text {enr }}$ in the UOx fabrication plant. UOx enrichment is calculated according to the PWR BU. After one irradiation cycle, the spent UOX fuel is cooled few years in a pool and sent in a stock that contains at this step Heavy Nuclides (HN) (uranium MA and plutonium) and FP. This stock and an infinite stock of depleted uranium $U_{\text {dep }}$ are used by the MOX fabrication plant to build MOX fuel. After one irradiation cycle in PWR MOX fuel, the spent fuel is cooled in a pool and sent in a stock. The MOX-EUS fuel is built from three streams: a plutonium stream extracted from spent fuels, a ${ }^{235} \mathrm{U}$ stream from an infinite stock and a $U_{\text {dep }}$ stream. The MOX-EUS fuel is charged in the reactor, sent to a cooling pool and sent back to the spent MOX stock in order to be reprocessed. Historical UOX and MOX spent fuel inventories produced by the French nuclear fleet up to 2015 are also introduced in this cycle. Two stocks are generated for this purpose and are composed by spent UOX and MOX in 2015. At each fresh fuel fabrication step, MA and FP are sent to a final stock and are not reused during the dynamic simulation.

In the framework of the design of experiments described above, trajectories simulated with the Fuel Cycle Simulator (FCS) CLASS starts in 2015. In order to have a fuel cycle description at this time which is representative of the French fleet, a detailed simulation has been done and has been described on the section 3.1. From this starting point, reactor power sampling set is represented on Figure 4.

The scenario starts at $\mathrm{T}_{0}=2015$ with a total effective thermal power $\mathrm{P}_{0}=137.13 \mathrm{GW}_{\text {th }}$ which corresponds to a total installed thermal power of $\mathrm{P}_{0}=188.11 \mathrm{GW}_{\text {th }}$ with a load factor of 0.729. Scenario ends at $\mathrm{T}_{\text {final }}=2115$ with an effective thermal power of $\mathrm{x}_{\mathrm{p}} \mathrm{P}_{0}$. Nevertheless, for output representation, the time will be labeled from 0 to 100 years. The thermal power decrease starts at the year $\mathrm{B}_{\mathrm{D}}=\mathrm{T}_{0}+10 \mathrm{y}$ and the decrease slope is constant up to the year $E_{D}$. MOX-EUS fuel is deployed instantly in PWR at the 


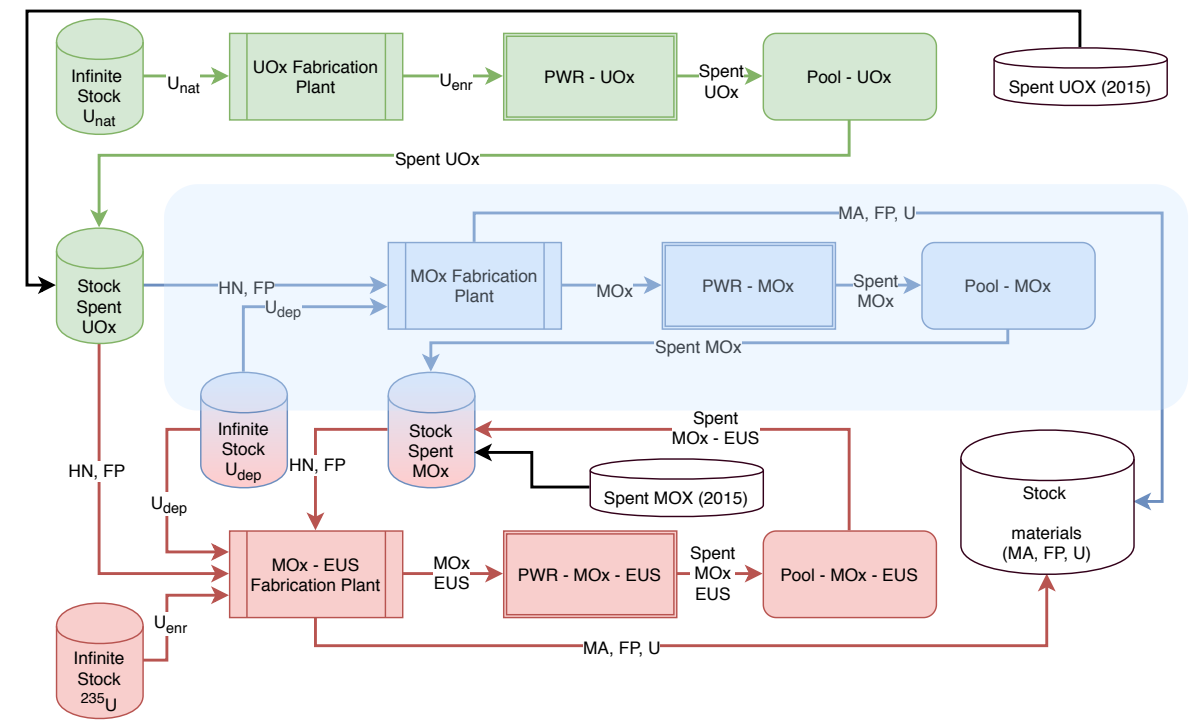

Figure 3: Schematic view of the fuel cycle simulations after 2015. Green facilities represent PWR UOX strata. Blue facilities represent PWR MOX components. The red part of the scheme is the PWR MOX-EUS that closes the fuel cycle for plutonium. Spent UOX and MOX in black are the homogeneous stocks obtained by the detailed French simulation until 2015.

year $\mathrm{B}_{\mathrm{E}}=\mathrm{T}_{0}+20 \mathrm{y}$. The fraction of PWR fueled with MOX-EUS power on the total thermal power is $\mathrm{x}_{\mathrm{E}}$. At this end of the scenario, after 100 years, the effective thermal power for PWR fueled with MOX-EUS is $\mathrm{x}_{\mathrm{E}} \mathrm{x}_{\mathrm{P}} \mathrm{P}_{0}$. Only a decrease of thermal power is supposed in order to be in agreement with the maximal capacity production of $63.2 \mathrm{GW}$ imposed by the National Energy Code [29]. All fuel fabrication times are set to 2 years. Plutonium separation efficiency is $100 \%$. The parameter for reactor models $\mathrm{k}_{\text {threshold }}$ has been set to 1.037 with 4 fuel loading batches. Load factors for reactors have been set to 0.73 . Before the time $\mathrm{B}_{\mathrm{E}}$ and during the power decrease, the MOX fraction, the $\mathrm{BU}$ and the MOX spent fuel cooling time are respectively $10 \%, 45 \mathrm{GWd} / \mathrm{t}$ and 8 years.

\subsection{Input variable space}

Variables and sampled technical parameters of the simulation have been reported in the Table 1. Those constraints have been defined according to technical hypotheses related to the future of the nuclear fleet. Reactor BU are typical PWR ranges. The 


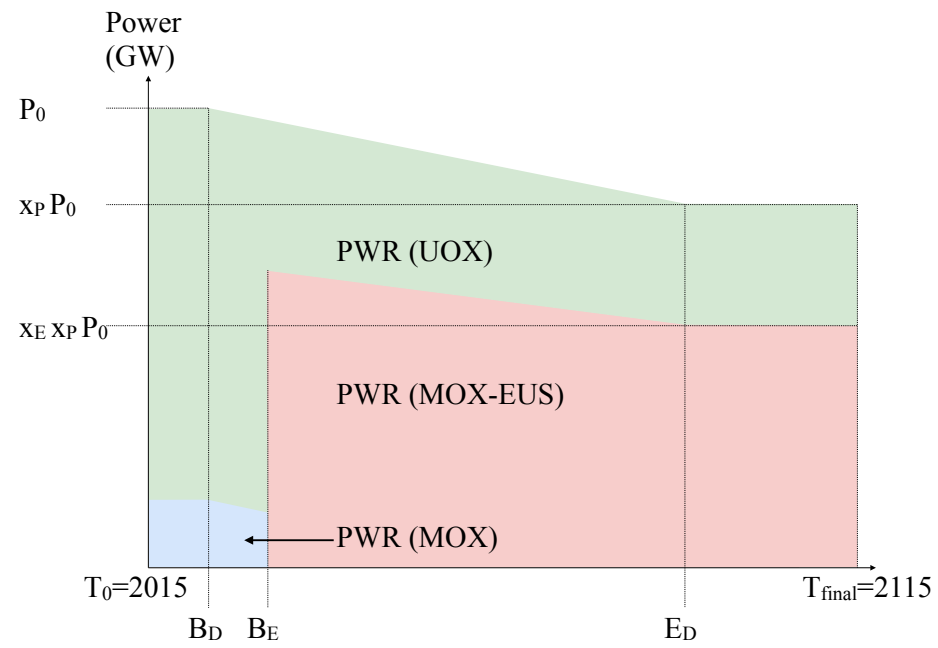

Figure 4: Trajectories space for the effective thermal power evolution of PWR fueled with UOX, MOX and MOX-EUS from 2015 to 2115.

fraction of the thermal power based on PWR MOX-EUS fuel is completely open, between 0 and $100 \%$.

The maximum plutonium content allowed in a MOX-EUS assembly is strongly dependent on the plutonium isotopic composition and fixing a precise value requires further system studies. To take into account safety aspects related to high plutonium content in the fuel, a plutonium maximum content range has been defined, between $8 \%$ and $13 \%$. This maximum plutonium content range is in agreement with typical values used in nuclear scenario studies [30]

Spent fuel cooling time can have an impact on material availability and composition. $E_{D}$ and $x_{P}$ range has been chosen in order to include a wide range of possibility for the evolution of the nuclear fleet. The plutonium stock management has been sampled on two values: LiFo (Last in First out) and FiFo (First in First out). In the LiFo management, the most recent plutonium is taken from the stock. In the FiFo management, the oldest plutonium in the stock is taken first. 
Table 1: Ranges used for sampled parameters used in CLASS simulations.

\begin{tabular}{|l|l|l|}
\hline Name & Sampled parameter & Range \\
\hline $\mathrm{BU}_{\mathrm{U}}$ & PWR UOX BU & {$[30,65] \mathrm{GWd} / \mathrm{t}$} \\
$\mathrm{BU}_{\mathrm{E}}$ & PWR MOX-EUS BU & {$[30,65] \mathrm{GWd} / \mathrm{t}$} \\
$\mathrm{x}_{\mathrm{E}}$ & PWR MOX-EUS fuel thermal power fraction & {$[0,1]$} \\
$\mathrm{w}_{\mathrm{Pu}}^{\mathrm{MAX}}$ & Maximum Pu content in the MOX-EUS & {$[0.8,0.13]$} \\
$\mathrm{T}_{\mathrm{c}}^{\mathrm{U}}$ & UOX fuel cooling time & {$[3,10]$ years } \\
$\mathrm{T}_{\mathrm{c}}^{\mathrm{E}}$ & MOX-EUS fuel cooling time & {$[3,10]$ years } \\
$\mathrm{E}_{\mathrm{D}}$ & End of the power decrease & {$[20,100]$ years } \\
$\mathrm{x}_{\mathrm{P}}$ & Ratio between final and initial thermal power & {$[0.01,1.0]$} \\
$\mathrm{G}_{\mathrm{s}}$ & Plutonium stock management & $\mathrm{LiFo}, \mathrm{FiFo}$ \\
\hline
\end{tabular}

\subsection{Design Of Experiments}

From this set of fixed and variable parameters, two DOE have been used. The first one is called $\mathrm{DOE}_{\text {Sobol }}$ and has been used to calculate Sobol' indices. $\mathrm{DOE}_{\text {Sobol }}$ is built from the method SobolSalt from the package Sensitivity [31] of the software environment for statistical computing and graphics R [32]. Two input samples have been built from a Monte-Carlo method. The total number of required runs is $M \times(2 N+2)$ where $N$ is the number of quantitative input variables ( 8 in this case) and $M$ is the number of runs in each sample. $M$ has been fixed at 2000, which imposes 36000 250 CLASS code callings, for each plutonium stock management. From this DOE, total, first and second order indices have been calculated for each input variables [33, 34]. The total Sobol' index represents the contribution of one input variable in the output variance. First order Sobol' index represents the contribution of one input variable alone in the output variance, while the second order index represents the contribution of the interaction of two input variables on the output variance.

The second one, $\mathrm{DOE}_{\mathrm{LHS}}$ is based on a Latin Hyper Square sampling on quantitative variables described in the Table 1 . This DOE is composed by 10000 CLASS simulations 
for each value of $\mathrm{G}_{\mathrm{s}}$, $\mathrm{LiFo}$ and $\mathrm{LiF}$. This DOE is used to analyze output variable of interest described in the next section.

A total of 92000 CLASS runs have been performed $(2 \times 36000+2 \times 10000)$ on the IN2P $3^{1}$ computing centre batch farm. The order of magnitude of the time required to run all these simulations is around the day.

\subsection{Output and nomenclature}

Each CLASS simulation produces a ROOT [35] output file that stores the simulation parameters and results. For each DOE, a global ROOT file is generated in order to gather results of interest. The total size of output data is around 20 Go. Structure of output files is composed by a list of events. Each event represents a CLASS simulation and contains the following stored data:

- Input parameters value

- Effective thermal power and cumulated energy evolution

- Transuranic mass evolution in facilities

The nomenclature for element mass consists in writing element in subscript and location in superscript. Elements can be $\mathrm{U}, \mathrm{Pu}$ or any $\mathrm{MA}(\mathrm{Np}, \mathrm{Am}$ or $\mathrm{Cm})$. Location can be any facility, stocks, pools and waste. Total represents the sum in the fleet. For The total plutonium mass in the fleet at this End of Scenario (EoS) is called $\mathrm{M}_{\mathrm{Pu}}^{\mathrm{tot}}(\mathrm{EoS})$.

\section{Scenario Output analysis}

This section aims to present raw output results in order to clarify and understand the simulation set.

\footnotetext{
${ }^{1}$ Institut national de physique nucléaire et de physique des particules
} 
Figure 5 shows evolution for the effective thermal power, the cumulated energy, the plutonium and MA masses evolution for the FiFo data set. Three random examples have been selected in order to highlight some trajectories.
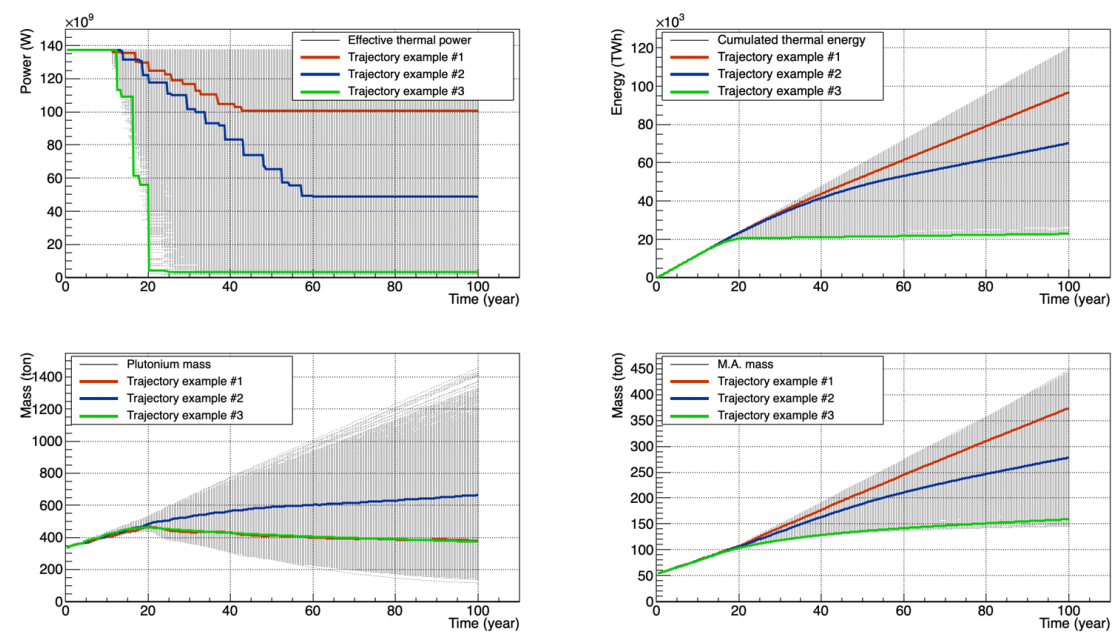

Figure 5: Effective thermal power (top left plot) evolution, cumulated energy production evolution (top right plot), total plutonium mass evolution (bottom left) and total minor actinides (bottom right) mass evolution for the FiFo set of data. Three random trajectory examples have been represented.

The Figure 5 shows that thermal power and cumulated energy range is very wide, from the continuation of nuclear at constant power to a fast phase out. Plutonium mass evolution is also very diversified. Some trajectories show plutonium incineration while other produce up to 1400 tons at EoS. Since there is no MA reprocessing considered in this work, all calculated trajectories are MA producer. MA mass at EoS ranges between 150 and 450 tons.

\subsection{Sobol' indices analyse}

Sobol' indices have been calculated and following nomenclature have been used :

- $\widehat{S}_{i}$ : First order Sobol' indices related to variable $i$

- $\widehat{S}_{i j}$ : Second order Sobol' indices related to the interaction of variable $i$ with variable $j$ 
The Table 2 presents Sobol' indices for the total plutonium mass at $\operatorname{EoS}\left(\mathrm{M}_{\mathrm{Pu}}^{\mathrm{tot}}(\mathrm{EoS})\right)$ and for the total plutonium and MA mass at $\mathrm{EoS}\left(\mathrm{M}_{\mathrm{Pu}+\mathrm{MA}}^{\mathrm{tot}}(\mathrm{EoS})\right)$. FiFo and LiFo management strategies for plutonium stocks used to build the MOX-EUS fuel are separated. Sobol' indices represented in the table are selected according to the value and the error on the value. If the error is higher than the value, the indices is not represented. As a consequence, only total and first order indices are represented, which means that second order interaction between variables are negligible in this case.

Table 2: First order, second order and total Sobol' indices estimation for output variables $\mathrm{M}_{\mathrm{Pu}}^{\mathrm{tot}}(\mathrm{EoS})$ and $\mathrm{M}_{\mathrm{Pu}+\mathrm{MA}}^{\mathrm{tot}}(\mathrm{EoS})$ at the end of the scenario.

\begin{tabular}{|c|c|c|c|}
\hline Fuel Strategy & Indices & $\begin{array}{c}\mathrm{M}_{\mathrm{Pu}}^{\mathrm{tot}}(\mathrm{EoS}) \\
\text { Index / Error }\end{array}$ & $\begin{array}{c}\mathrm{M}_{\mathrm{Pu}+\mathrm{MA}}^{\mathrm{tot}}(\mathrm{EoS}) \\
\text { Index / Error }\end{array}$ \\
\hline \multirow{7}{*}{ LiFo } & $\widehat{S}_{\mathrm{BU}_{\mathrm{U}}}$ & $0.032 / 0.024$ & $0.033 / 0.021$ \\
\hline & $\widehat{S}_{\mathrm{X}_{\mathrm{E}}}$ & $0.825 / 0.005$ & $0.648 / 0.013$ \\
\hline & $\widehat{S}_{\mathrm{XP}}$ & $0.097 / 0.024$ & $0.260 / 0.019$ \\
\hline & $\widehat{T}_{\mathrm{BU}_{\mathrm{U}}}$ & $0.032 / 0.001$ & $0.032 / 0.001$ \\
\hline & $\widehat{T}_{\mathrm{X}_{\mathrm{E}}}$ & $0.875 / 0.024$ & $0.691 / 0.017$ \\
\hline & $\widehat{T}_{\mathrm{E}_{\mathrm{D}}}$ & 0.014 / 0.001 & $0.030 / 0.001$ \\
\hline & $\widehat{T}_{\mathrm{XP}}$ & $0.131 / 0.005$ & $0.300 / 0.010$ \\
\hline \multirow{7}{*}{ FiFo } & $\widehat{S}_{\mathrm{BU}_{\mathrm{U}}}$ & $0.036 / 0.021$ & $0.034 / 0.020$ \\
\hline & $\widehat{S}_{\mathrm{XE}_{\mathrm{E}}}$ & $0.820 / 0.007$ & $0.650 / 0.012$ \\
\hline & $\widehat{S}_{\mathrm{XP}}$ & $0.110 / 0.021$ & $0.260 / 0.018$ \\
\hline & $\widehat{T}_{\mathrm{BU}_{\mathrm{U}}}$ & $0.033 / 0.001$ & $0.032 / 0.002$ \\
\hline & $\widehat{T}_{\mathrm{X}_{\mathrm{E}}}$ & $0.860 / 0.022$ & $0.690 / 0.017$ \\
\hline & $\widehat{T}_{\mathrm{E}_{\mathrm{D}}}$ & $0.013 / 0.001$ & $0.030 / 0.002$ \\
\hline & $\widehat{T}_{\mathrm{XP}}$ & $0.140 / 0.005$ & $0.300 / 0.001$ \\
\hline
\end{tabular}


Sobol' indices for LiFo and FiFo plutonium management strategy are compatible within the errors. Four variables are represented : $\mathrm{BU}_{U}, \mathrm{x}_{\mathrm{E}}, \mathrm{E}_{\mathrm{D}}, \mathrm{x}_{\mathrm{P}}$. The fraction of PWR MOX-EUS $\mathrm{x}_{\mathrm{E}}$ is by far the most important variable involved in the variance of the outputs $\mathrm{M}_{\mathrm{Pu}}^{\mathrm{tot}}(\mathrm{EOS})$ and $\mathrm{M}_{\mathrm{Pu}+\mathrm{MA}}^{\mathrm{tot}}(\mathrm{EoS})$ since total and first order Sobol' indices are between $80 \%$ and $90 \%$. The ratio between final and initial thermal power $\mathrm{x}_{\mathrm{P}}$ has a smaller impact on outputs variance with a total and first order Sobol' indices close to $10 \%$. The BU of the PWR UOX has a limited effect that is quantified by Sobol' indices around 3\%, very close to the statistical errors. The time at which the power ends decreasing $\left(E_{D}\right)$ presents a small value of total Sobol' indices and negligible for the first and second order indices.

The role of $x_{E}$ in the output variance is quite clear. All other factors being equal, the higher $\mathrm{x}_{\mathrm{E}}$ is, the higher the plutonium consumption rate is and the smaller plutonium inventory is at the end of the scenario. This can be confirmed by the plot represented on Figure 6 which represents $\mathrm{M}_{\mathrm{Pu}}^{\mathrm{tot}}(\mathrm{EoS})$ and $\mathrm{M}_{\mathrm{Pu}+\mathrm{MA}}^{\mathrm{tot}}(\mathrm{EoS})$ according to $\mathrm{x}_{\mathrm{E}}$ and $\mathrm{x}_{\mathrm{P}}$ for the LiFo set of data.
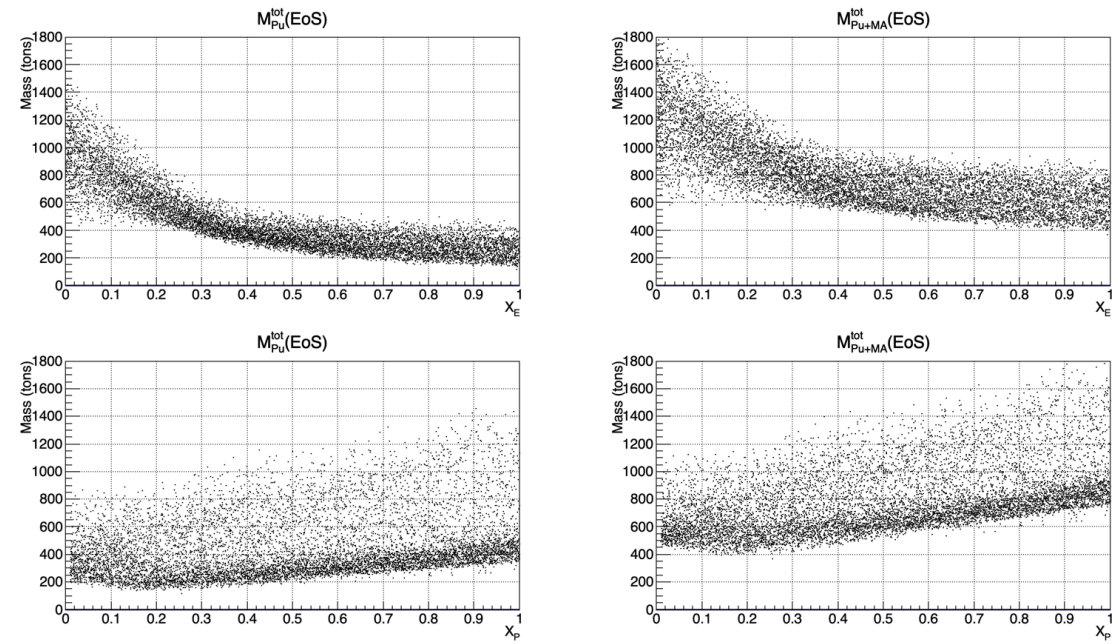

Figure 6: $\mathrm{M}_{\mathrm{Pu}}^{\text {tot }}(\mathrm{E} O \mathrm{~S})$ and $\mathrm{M}_{\mathrm{Pu}+\mathrm{MA}}^{\text {tot }}($ EoS $)$ dependency according to $\mathrm{x}_{\mathrm{E}}$ for the LiFo Design Of Experiment (first row). $\mathrm{M}_{\mathrm{Pu}}^{\text {tot }}(E \circ S)$ and $\mathrm{M}_{\mathrm{Pu}+\mathrm{MA}}^{\text {tot }}(\mathrm{EOS})$ dependency according to $\mathrm{x}_{\mathrm{P}}$ for the LiFo Design Of Experiment (second row).

The impact of $\mathrm{x}_{\mathrm{P}}$ is more difficult to assess. If $\mathrm{x}_{\mathrm{P}}$ is very small, that means the fleet 
thermal power tends to zero which is a nuclear phase out during the scenario. A phase into ${ }^{241} \mathrm{Am}$ ) while the total inventory of plutonium and MA is constant. If $\mathrm{x}_{\mathrm{P}}$ increases, the impact on plutonium and MA inventory depends on those elements balance in the fleet. If the fleet produces $\mathrm{Pu}$ (respectively $\mathrm{Pu}+\mathrm{MA}$ ) in average, the final inventory of $\mathrm{Pu}$ (respectively $\mathrm{Pu}+\mathrm{MA}$ ) will be higher. On the other hand, if the fleet is $\mathrm{Pu}$ incinerator enrichment. In those conditions, such a reactor should be considered as an PWR UOX even though it is recorded as a PWR MOX-EUS. In order to discriminate this kind of behavior, an additional output, < U5 Enr. > has been produced and represents the average uranium enrichment in fresh fuel at each reactor loading in the given trajectory. fixed, NL depends on the reactor cycle time which is calculated from the reactor BU. The ratio between the ${ }^{235} \mathrm{U}$ mass at Beginning of Cycle $(\mathrm{BoC})\left(\mathrm{M}_{235}^{\mathrm{MOXEUS}}(\mathrm{BOC})\right)$ in the PWR MOX-EUS and the heavy nuclides fuel mass $\left(\mathrm{M}_{\text {fuel }}\right)$ represents the fresh fuel 
${ }^{235} \mathrm{U}$ enrichment. This output variable will be used to control the PWR MOX-EUS characteristics.

This will be completed by the average plutonium content at $\mathrm{BoC}$ in a trajectory calculated as the ratio of the plutonium mass in the reactor $\mathrm{BoC}\left(\mathrm{M}_{\mathrm{Pu}}^{\mathrm{MOX}-\mathrm{EUS}}(\mathrm{BoC})\right)$ and the heavy nuclides fuel mass $\left(\mathrm{M}_{\text {fuel }}\right)$.

Finally, the cumulated thermal energy at $\operatorname{EoS}\left(\mathrm{E}_{\mathrm{th}}(\mathrm{EoS})\right)$ has been calculated for each trajectory as the thermal power integration on time. This output will provide additional information on the nuclear power evolution.

Table 3: Output parameters of interest for the analyze of simulation data set. Sums are done on all reactor loadings in the scenario.

\begin{tabular}{|c|c|c|}
\hline Label & Definition & Unit \\
\hline$\Delta \mathrm{M}_{\mathrm{Pu}}^{\mathrm{tot}}(\mathrm{A})$ & $\mathrm{M}_{\mathrm{Pu}}^{\mathrm{tot}}(\mathrm{EoS})-\mathrm{M}_{\mathrm{Pu}}^{\mathrm{tot}}(20 \mathrm{y})$ & tons \\
\hline$\Delta \mathrm{M}_{\mathrm{Pu}}^{\mathrm{tot}}(\mathrm{B})$ & $\mathrm{M}_{\mathrm{Pu}}^{\mathrm{tot}}(\mathrm{EoS})-\mathrm{M}_{\mathrm{Pu}}^{\mathrm{tot}}(60 \mathrm{y})$ & tons \\
\hline$\Delta \mathrm{M}_{\mathrm{Pu}}^{\mathrm{tot}}(\mathrm{C})$ & $\mathrm{M}_{\mathrm{Pu}}^{\mathrm{tot}}(60 \mathrm{y})-\mathrm{M}_{\mathrm{Pu}}^{\mathrm{tot}}(20 \mathrm{y})$ & tons \\
\hline$\Delta \mathrm{M}_{\mathrm{Pu}+\mathrm{MA}}^{\mathrm{tot}}(\mathrm{A})$ & $\mathrm{M}_{\mathrm{Pu}+\mathrm{MA}}^{\mathrm{tot}}(\mathrm{EoS})-\mathrm{M}_{\mathrm{Pu}+\mathrm{MA}}^{\mathrm{tot}}(20 \mathrm{y})$ & tons \\
\hline$\Delta \mathrm{M}_{\mathrm{Pu}+\mathrm{MA}}^{\mathrm{tot}}(\mathrm{B})$ & $\mathrm{M}_{\mathrm{Pu}+\mathrm{MA}}^{\mathrm{tot}}(\mathrm{EoS})-\mathrm{M}_{\mathrm{Pu}+\mathrm{MA}}^{\mathrm{tot}}(60 \mathrm{y})$ & tons \\
\hline$\Delta \mathrm{M}_{\mathrm{Pu}+\mathrm{MA}}^{\mathrm{tot}}(\mathrm{C})$ & $\mathrm{M}_{\mathrm{Pu}+\mathrm{MA}}^{\mathrm{tot}}(60 \mathrm{y})-\mathrm{M}_{\mathrm{Pu}+\mathrm{MA}}^{\mathrm{tot}}(20 \mathrm{y})$ & tons \\
\hline $\begin{array}{l}<\text { U5 Enr. }> \\
<\text { Pu Frac. }>\end{array}$ & $\begin{array}{l}\frac{\sum_{\mathrm{i}=1}^{\mathrm{i}=\mathrm{NL}} \mathrm{M}_{\mathrm{US}}^{\mathrm{MOX}-\mathrm{EUS}}\left(\mathrm{BOC}_{\mathrm{i}}\right) / \mathrm{M}_{\text {fuel }}}{\mathrm{NL}} \\
\frac{\sum_{\mathrm{i}=1}^{\mathrm{i}=\mathrm{NL}} \mathrm{M}_{\mathrm{Pu}}^{\mathrm{MOO}-\mathrm{EUS}}(\mathrm{BoC}) / \mathrm{M}_{\text {fuel }}}{\mathrm{NL}}\end{array}$ & \\
\hline$\Delta \mathrm{E}_{\mathrm{th}}$ & $\int_{\mathrm{t}=20 \mathrm{y}}^{\mathrm{t}=\mathrm{EoS}} \mathrm{P}_{\mathrm{th}}(\mathrm{t}) \mathrm{dt}$ & TWh \\
\hline
\end{tabular}

No important differences have been observed between LiFo and FiFo strategies for plutonium stock management. As a consequence, all following results will be presented for the FiFo data set.

\section{Plutonium stabilization}

In this section, the stabilization of the plutonium inventory will be investigated. 


\section{1. stabilization criteria}

The plutonium stabilization condition is based on the output observable $\Delta \mathrm{M}_{\mathrm{Pu}}^{\mathrm{tot}}(\mathrm{A})$, $\Delta \mathrm{M}_{\mathrm{Pu}}^{\mathrm{tot}}(\mathrm{B})$ and $\Delta \mathrm{M}_{\mathrm{Pu}}^{\mathrm{tot}}(\mathrm{C})$. The plutonium stabilization criteria are following :

$$
-20 \text { tons }<\Delta \mathrm{M}_{\mathrm{Pu}}^{\mathrm{tot}}(\mathrm{A}, \mathrm{B}, \mathrm{C})<20 \text { tons }
$$

A \pm 20 tons deviation is allowed on a plutonium mass. Using two more criteria by splitting trajectories aims to remove bell curve trajectories that would respect $\Delta \mathrm{M}_{\mathrm{Pu}}^{\text {tot }}(\mathrm{A})$ criterion by accident. The Figure 7 shows plutonium evolution for the FiFo data set and for the plutonium stabilization selection obtained by application of criteria described above.

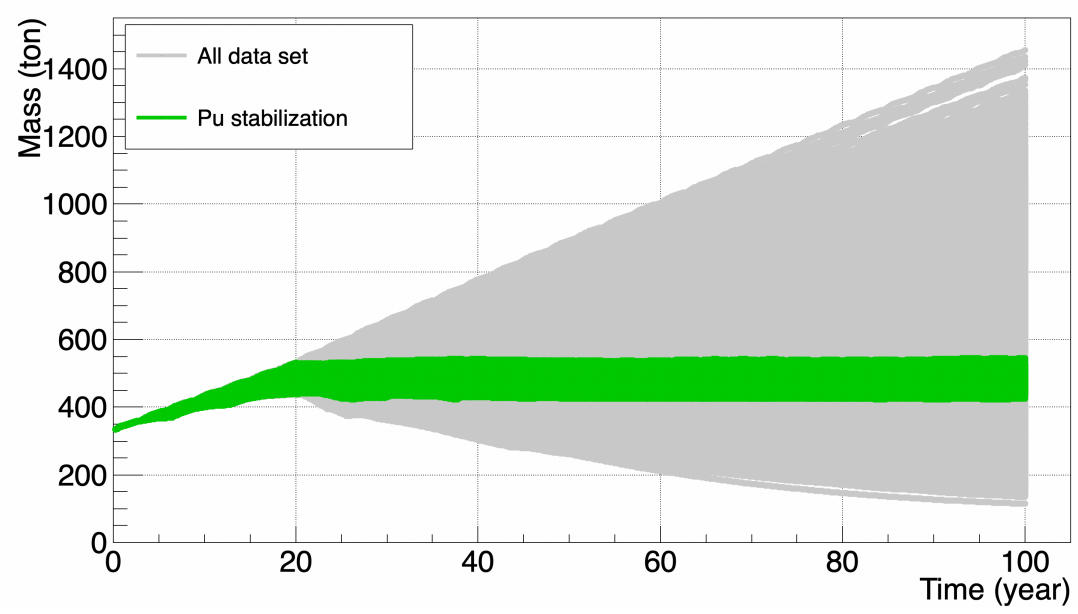

Figure 7: Total plutonium evolution for the FiFo data set (gray lines). Trajectories obtained after plutonium stabilization criteria are highlighted in green.

The plutonium mass evolution is constant as expected and ranges between 400 and 550 tons at EoS. In order to identify input variables space for which plutonium is stabilized, parallel plots are generated and shown on Figure 8. Three cuts have been imposed on $<$ Pu Frac. $>$ parameter for the readability. This highlights the fact that some stabilization trajectories are characterized by small plutonium content (blue selection on the Figure 8 and a high uranium enrichment. Those trajectories allow 


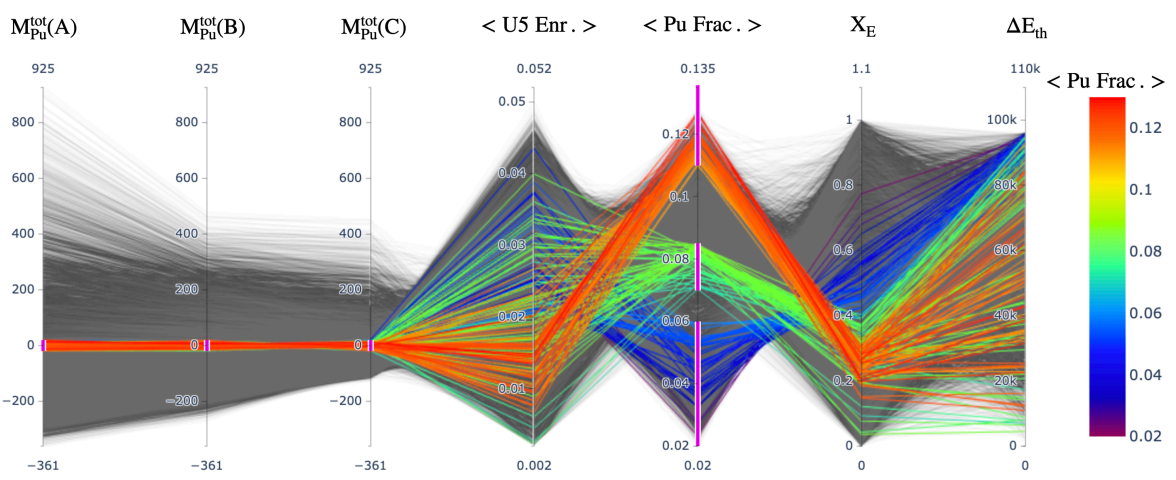

Figure 8: Parallel plot built from the FiFo data set. Gray lines represent all the simulations. Colored lines are trajectories that stabilize the total plutonium mass. Colored right scale is a color code based on the plutonium fraction at beginning of the reactor cycle averaged on each trajectory. Each vertical line is a variable defined in the text. For readability, three cuts have been imposed on $<$ Pu Frac. $>$.

higher PWR MOX-EUS fraction ( $\mathrm{x}_{\mathrm{E}} \sim 0.5$ ) with high values for $\mathrm{x}_{\mathrm{P}}$, which means almost constant power nuclear fleet. The higher value of $\mathrm{x}_{\mathrm{E}}$ is a bias since PWR MOXEUS behaves as a UOX. As a consequence, the plutonium stabilization input space assessment must consider only high plutonium content to have a non-biased value of $\mathrm{x}_{\mathrm{E}}$. as a consequence, following cut has been imposed on $<\mathrm{Pu}$ Frac. $>$ :

$<$ Pu Frac. $>\geq 0.07$

Also, small values of $\mathrm{x}_{\mathrm{E}}\left(\mathrm{x}_{\mathrm{E}} \leq 0.2\right)$ leads to really low cumulated thermal energy. That means those trajectories represent the short term nuclear phase out in which plutonium is close to equilibrium because there are no reactors in operation. An additional cut $\left(\mathrm{E}_{\mathrm{th}}(\mathrm{E} \mathrm{S}) \geq 20 \cdot 10^{E} T W h\right)$ is then imposed.

\subsection{Input variables distributions}

The final distribution for $\mathrm{x}_{\mathrm{E}}$ and interactions with important input data are shown on Figure 9. In the case of Pu stabilization, $\mathrm{x}_{\mathrm{E}}$ is represented by a normal distribution, with a 4.5\% standard deviation. The PWR MOX-EUS fraction that stabilizes the plutonium is around $30 \%$. Nevertheless, this value is highly correlated with other input variables. $\mathrm{x}_{\mathrm{E}}$ and $\mathrm{x}_{\mathrm{P}}$ are positively correlated, which means that a higher fraction of PWR MOX-EUS 

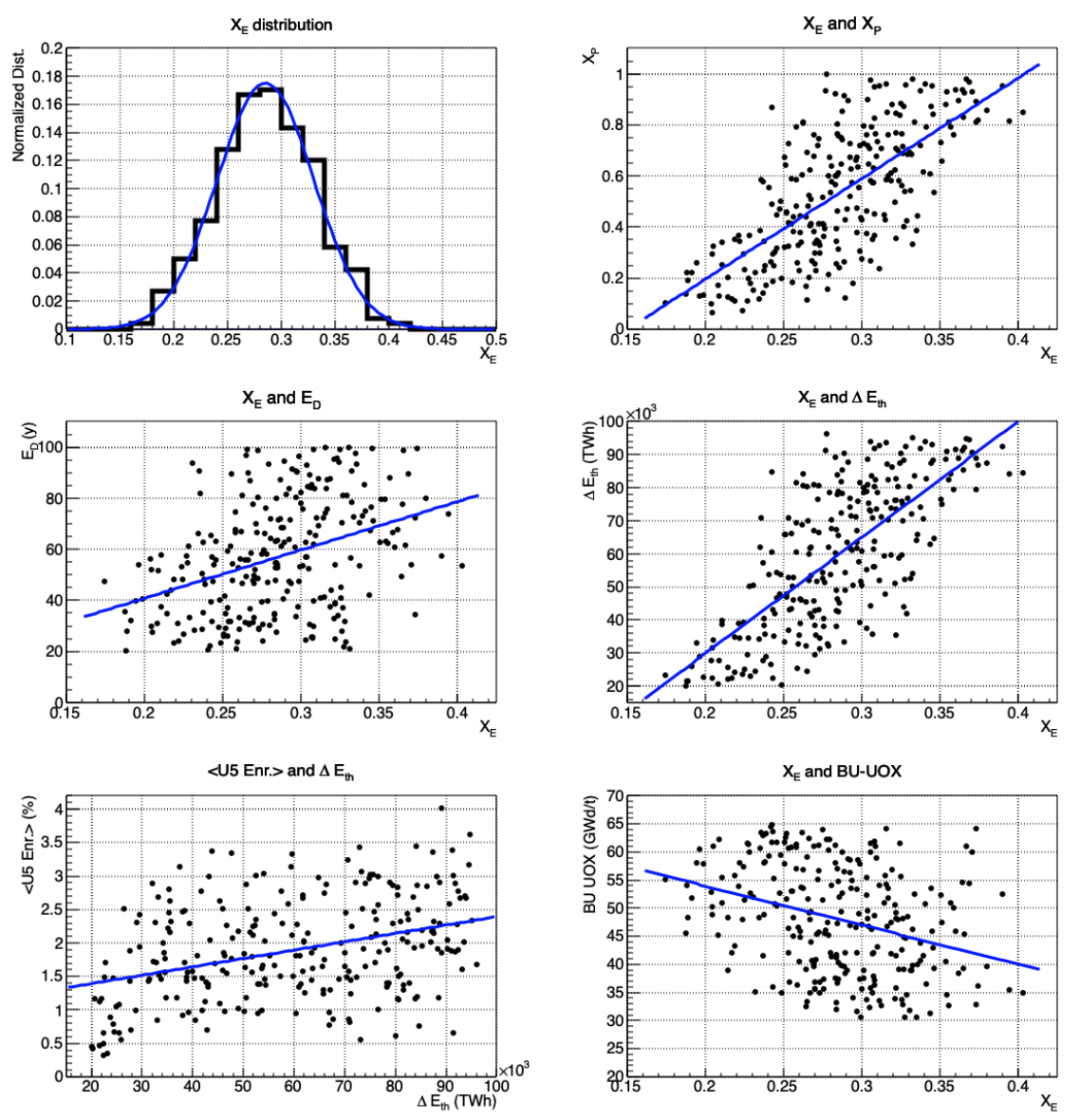

Figure 9: $x_{\mathrm{E}}$ final distribution for the FiFo data set induced by the plutonium stabilization (top left) fitted by a normal distribution. Interaction of $\mathrm{x}_{\mathrm{E}}$ with $\mathrm{x}_{\mathrm{P}}$ (top right), $\mathrm{E}_{\mathrm{D}}$ (middle left), $\Delta \mathrm{E}_{\mathrm{th}}$ (middle right) and $\mathrm{BU} \mathrm{UOX}$ (bottom right) are represented. The bottom left plot represents the average enrichment in ${ }^{235} \mathrm{U},<\mathrm{U} 5 \mathrm{Enr} .>$ versus $\Delta \mathrm{E}_{\text {th }}$. First-order polynomial fitted functions are also represented in blue.

are required to stabilize the plutonium if the fleet power is kept high. The conclusion is equivalent when looking at $\Delta \mathrm{E}_{\mathrm{th}}$ interaction with $\mathrm{x}_{\mathrm{E}}$. The role of $E_{D}$ is much smaller. To explain these observations, we recall that the plutonium equilibrium comes from a competition between reactors that produce plutonium (PWRs UOX) and reactors that incinerate plutonium (PWRs MOX-EUS). If the nuclear power is kept high, plutonium mass in PWR MOX-EUS is high. To give an order of magnitude of plutonium mass involved, let consider the French fleet described above. The total heavy nuclides mass 
in reactors, $\mathrm{M}_{\mathrm{HN}}^{\text {Reac. }}$, is given by :

$$
\mathrm{M}_{\mathrm{HN}}^{\text {Reac. }}=34 \times 75.5+20 \times 104+4 \times 110=587 \text { tons }
$$

Having $30 \%$ of the fleet dedicated to the multi-reprocessing of the plutonium with reactors loaded with around $10 \%$ of plutonium means that around 150 tons is mobilized in the PWR MOX-EUS. A rough factor 3 can be applied to take into account the interim storage of the plutonium ( 2 years for fuel fabrication and 5 years for spent fuel cooling). The final order of magnitude is around 450 tons, closed to the initial plutonium mass. This means that a tightness on plutonium may occur for trajectories characterized by a

405 high power. As a consequence, high-power trajectories will need more enrichment in ${ }^{235} \mathrm{U}$. The plot representing < U5 Enr. $>$ as a function of $\Delta \mathrm{E}_{\text {th }}$ (third row, left) shows that ${ }^{235} \mathrm{U}$ enrichment doubles between small and high values of $\Delta \mathrm{E}_{\mathrm{th}}$.

The BU UOX interaction with $\mathrm{x}_{\mathrm{E}}$ shows that a small value of $\mathrm{BU}$ required a high value of $\mathrm{x}_{\mathrm{E}}$ in order to stabilize the plutonium inventory. This can be interpreted by the fact that the plutonium generation rate is higher for smaller BU and the plutonium mass to manage is also higher. Statistical parameters of input variable distributions are summarized in the Table 4.

Table 4: Statistical parameters for input variable distributions in the case of plutonium stabilization obtained from the FiFo data set.

\begin{tabular}{|l|l|l|l|l|l|}
\hline Variable & $\mathrm{x}_{\mathrm{E}}$ & $\mathrm{x}_{\mathrm{P}}$ & $\mathrm{E}_{\mathrm{D}}$ & $\mathrm{BU} U \mathrm{UOX}$ & $\Delta \mathrm{E}_{\mathrm{th}}$ \\
\hline mean & $2.910^{-1}$ & $5.310^{-1}$ & $5.710^{1}$ & $4.810^{1}$ & $6.010^{4}$ \\
\hline std & $4.510^{-2}$ & $2.510^{-1}$ & $2.210^{1}$ & 9.6 & $2.210^{4}$ \\
\hline $\min$ & $1.710^{-1}$ & $6.610^{-2}$ & $2.010^{1}$ & $3.110^{1}$ & $2.010^{4}$ \\
\hline $\max$ & $4.010^{-1}$ & 1.0 & $1.010^{2}$ & $6.510^{1}$ & $9.610^{4}$ \\
\hline
\end{tabular}

\subsection{Minor Actinides production}

The Figure 10 represents the ratio between MA and plutonium mass at EoS. This 415 ratio ranges between $40 \%$ and $100 \%$. The plot also shows that MA production increases with $\mathrm{x}_{\mathrm{E}}$. This is explained by the fact that increasing the plutonium irradiation 
produces more MA by neutron capture on plutonium. In addition, it shows that MA inventory order of magnitude is very comparable to plutonium inventory at EoS. As a consequence, the MA should be taken into account in the framework of high mass inventory stabilization. This is investigated in the following section.

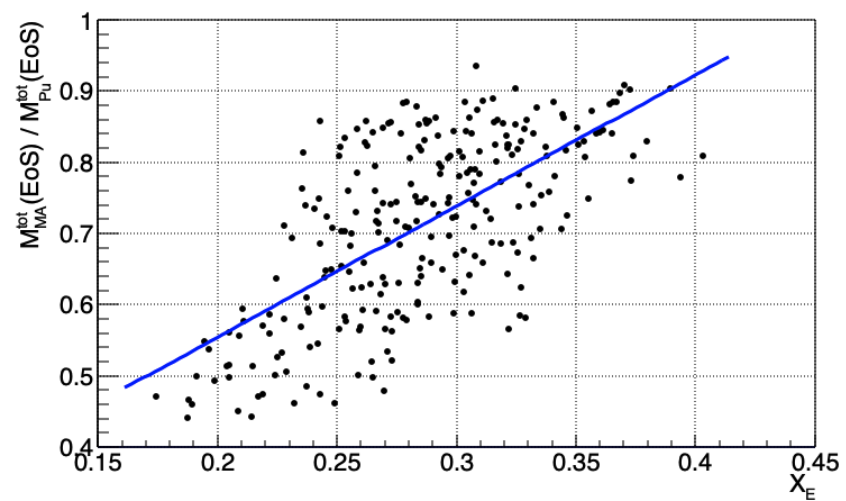

Figure 10: Ratio between minor actinides mass and plutonium mass at the end of the scenario as a function of $\mathrm{x}_{\mathrm{E}}$. First-order polynomial fitted functions are also represented in blue.

In order to have a global vision of trajectories that allow plutonium stabilization, the power evolution for the final subset of data is represented on Figure 11. Two extreme trajectories have been highlighted. The first one corresponds to the smallest value for $\Delta \mathrm{E}_{\text {th }}$ (red line) and the second one is the highest (blue line). Two random trajectories (green and pink lines) are also highlighted.

\subsection{Plutonium stabilization summary}

To close this section related to the plutonium stabilization, the following summary is proposed. Among all the simulated trajectories involving multi-reprocessing of plutonium in PWR MOX-EUS, some of them show plutonium inventory stabilization. However, part of them includes PWR MOX-EUS loaded with highly enriched uranium and low plutonium content. This has to be investigated in order to avoid bias when connecting criteria with input variables. Indeed, the value of $\mathrm{x}_{\mathrm{E}}$ for those simulations is not correct since some PWR MOX-EUS should be counted as PWR UOX. To avoid these simulations, a cut has been set on the plutonium fraction in fresh MOX-EUS fuel 


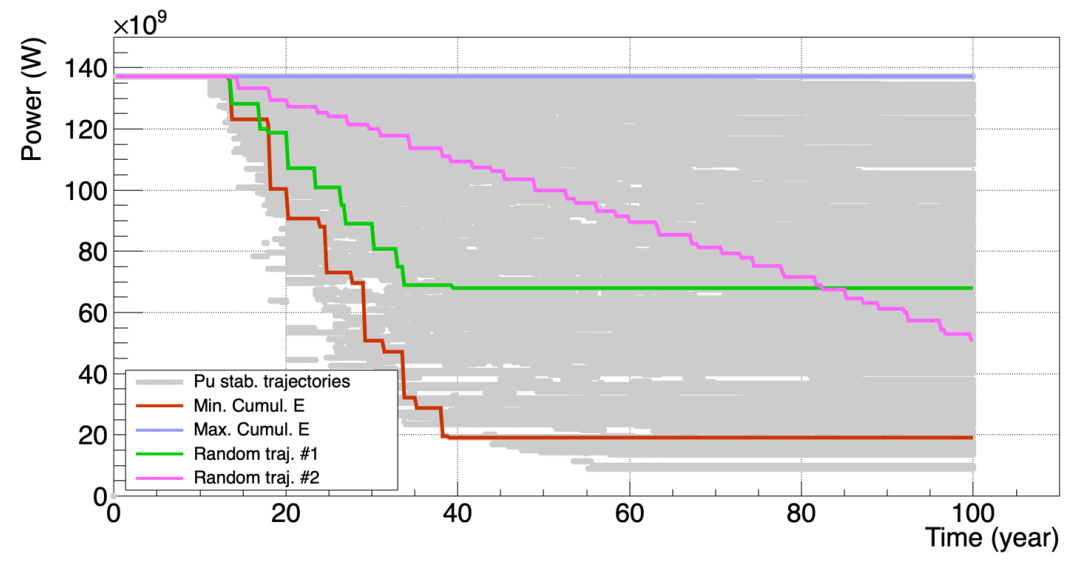

Figure 11: Thermal power evolution for the FiFo data set obtained from the application of plutonium stabilization criteria. Gray lines represent the whole data set. The red line (respectively blue line) is the trajectory that involves the smallest (respectively highest) value of $\Delta \mathrm{E}_{\mathrm{th}}$. Two random examples (green and pink lines) have been added.

${ }_{435}<$ Pu Frac. $><7 \%$. Furthermore, some plutonium stabilizing simulations correspond to the trivial solution of short term nuclear phase out. A cut on cumulated thermal energy has also been set $\left(\Delta \mathrm{E}_{\mathrm{th}}>20 \cdot 10^{3} \mathrm{TWh}\right)$.

The remaining simulations present an effective stabilization of plutonium inventory. The most important variable to achieve this goal is the PWR MOX-EUS fraction in the fleet, $\mathrm{x}_{\mathrm{E}}$. Plutonium stabilization criteria lead to a normal distribution for $\mathrm{x}_{\mathrm{E}}$ centered in the value $30 \%$. The interaction with other variables is not negligible and has to be taken into account. The nuclear power evolution does not affect the feasibility of the plutonium stabilization. This goal is achievable whatever the future of nuclear power is. Nevertheless, this induces the production of MA, between $40 \%$ and $100 \%$ of the ${ }_{445}$ plutonium mass at EoS, so after 80 years of MOX-EUS utilization.

\section{Transuranic stabilization}

In this section, the simultaneous stabilization of the plutonium and MA will be investigated. There is no MA reprocessing in the scenarios considered in this work (see Figure 3). As a consequence, MA net production rate evolution is always positive 
even for phase-out trajectories since ${ }^{241} \mathrm{Pu}$ decreased to ${ }^{241} \mathrm{Am}$. The stabilization of transuranic elements involves then a reduction of plutonium inventory that compensates exactly the MA production.

\subsection{Stabilization criteria}

Transuranic stabilization criteria are based on the output observable $\Delta \mathrm{M}_{\mathrm{Pu}+\mathrm{MA}}^{\mathrm{tot}}(\mathrm{A})$, $\Delta \mathrm{M}_{\mathrm{Pu}+\mathrm{MA}}^{\mathrm{tot}}(\mathrm{B})$ and $\Delta \mathrm{M}_{\mathrm{Pu}+\mathrm{MA}}^{\mathrm{tot}}(\mathrm{C})$. In order to have an appropriate number of valid trajectories, stabilization criteria have been defined as similarly to plutonium stabilization criteria:

$$
-20 \text { tons }<\Delta \mathrm{M}_{\mathrm{Pu}+\mathrm{MA}}^{\mathrm{tot}}(\mathrm{A}, \mathrm{B}, \mathrm{C})<20 \text { tons }
$$

This means that the sum of plutonium and MA mass deviation is constrained between -20 and +20 tons. The parallel plot composed by variables of interest is represented on Figure 12. Three cuts on the variable $<$ Pu Frac. $>$ have been imposed in order to highlight the PWR MOX-EUS characteristics.

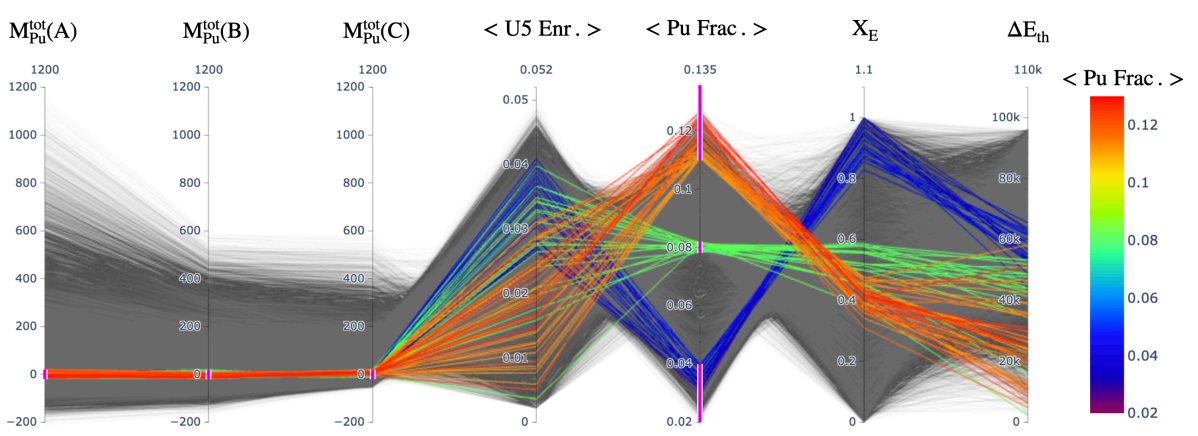

Figure 12: Parallel plot built from the FiFo data set. Gray lines represent all the simulations. Colored lines are trajectories that stabilize the total plutonium mass. Colored right scale is a color code based on the plutonium fraction at beginning of the reactor cycle averaged on each trajectory. Each vertical line is a variable defined in the text. For readability, three cuts have been imposed on $<$ Pu Frac. $>$.

As for the case of plutonium stabilization, those three cuts show that some very low $<$ Pu Frac. $>$ trajectories, representative of PWR UOX rather than MOX-EUS, are associated with very high value of $\mathrm{x}_{\mathrm{E}}$ and a significative value of $\Delta \mathrm{E}_{\mathrm{th}}$. This suggests that 
some trajectories seem to stabilize transuranic elements with a high fraction of MOXEUS and a high energy produced. Nevertheless, those trajectories are characterized by a bias on the $\mathrm{x}_{\mathrm{E}}$ value and have to be removed from the analysis. For this purpose, the $<$ Pu Frac. $>$ variable is imposed to be higher than 7\%. Some trajectories, represented by a very small value of $\Delta \mathrm{E}_{\mathrm{th}}$, are solutions of the stabilization conditions. Those 470 trajectories are closed to fast nuclear phase out and are as a consequence trivial solutions. For this reason, trajectories with $\Delta \mathrm{E}_{\mathrm{th}}$ smaller than $20000 \mathrm{TWh}$ are also removed from the analysis.

\subsection{Input variables distribution}

After applying criteria described above, the final distributions for plutonium and

For this reason, input variables are represented in interaction with it. $\mathrm{x}_{\mathrm{E}}$ distribution (top left plot) shows that around 50\% of PWR MOX-EUS are required to stabilize the total transuranic inventory. The interaction between $\mathrm{x}_{\mathrm{E}}$ and $\mathrm{x}_{\mathrm{P}}$ (top right plot) is small, slightly positive, and $\mathrm{x}_{\mathrm{P}}$ ranges between 0 and $50 \%$. The interaction with $\mathrm{E}_{\mathrm{D}}$ is also

480 small but shows a positive relation with $\mathrm{x}_{\mathrm{E}}$. The representation of $\Delta \mathrm{E}_{\text {th }}$ versus $\mathrm{x}_{\mathrm{E}}$ shows a positive relation. Indeed, a high reduction of the nuclear power during the scenario involves a smaller fraction of PWR MOX-EUS, around 40\%, while around $60 \%$ are required in the high-energy production scenarios that stabilize plutonium and minor actinides. As for the case of the plutonium inventory stabilization, this is mainly due to a low plutonium availability, in high energy producer trajectories, which leads a low plutonium fraction in MOX-EUS fresh fuel at the reactor BoC. As a consequence, a higher fraction of the power has to be dedicated to PWR MOX-EUS to compensate plutonium production in PWR UOX.

Finally, the interaction between the BU of the PWR UOX and $\mathrm{x}_{\mathrm{E}}$ is small and slightly negative. Again, a smaller BU produces more plutonium and with a high fissile content. This means more PWR MOX-EUS for the transuranic stabilization.

The input variables characteristics are computed on the Table 5. If the PWR MOXEUS fraction has to be around 50\%, the final thermal power $\left(x_{P}\right)$ average is $21 \%$ of the initial thermal power with a final end of power decrease average time $\left(E_{D}\right)$ close to 60 

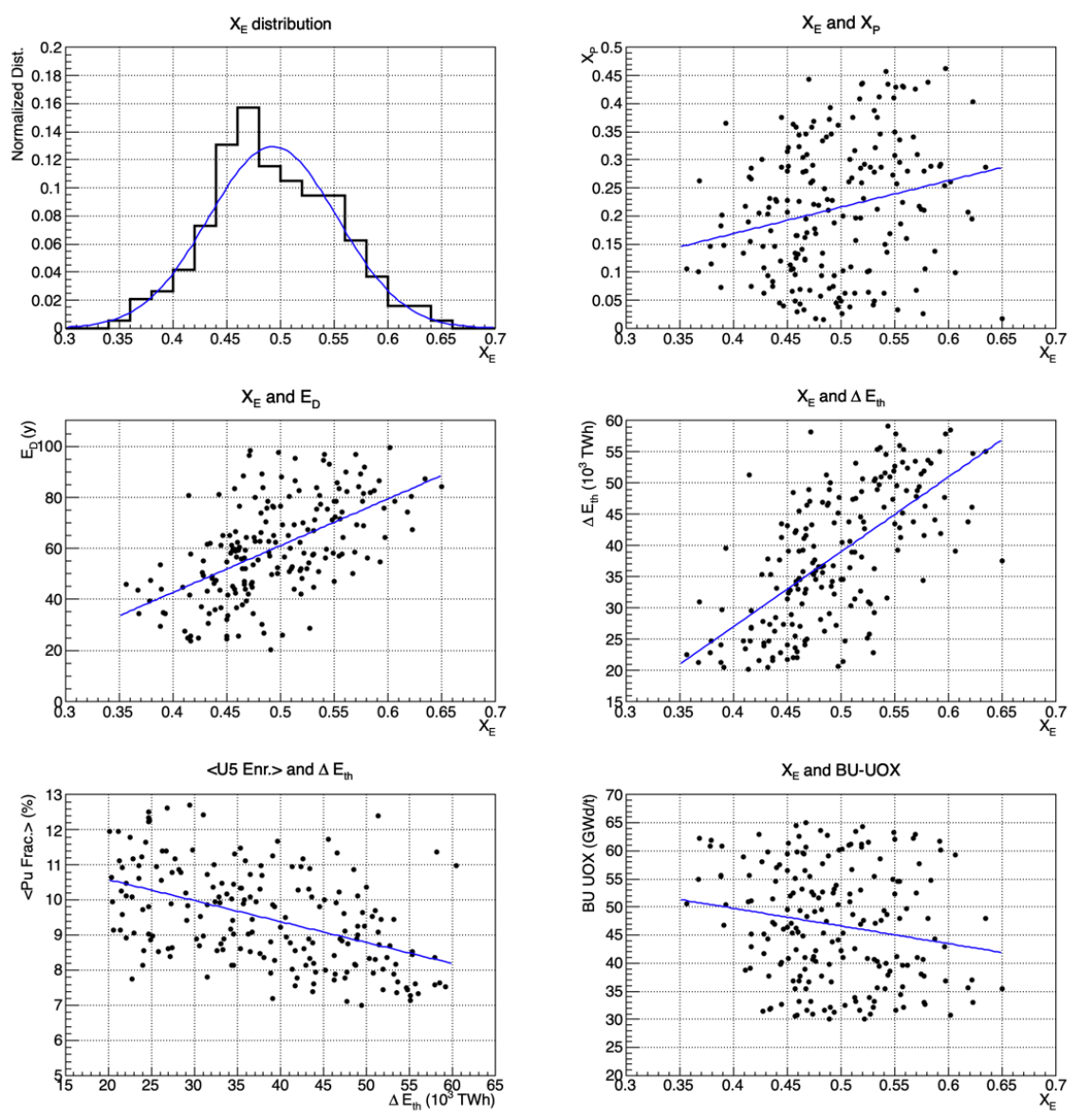

Figure 13: $\mathrm{x}_{\mathrm{E}}$ final distribution for the FiFo data set induced by the transuranic (plutonium and minor actinides) stabilization (top left) fitted by a normal distribution. Interaction of $\mathrm{x}_{\mathrm{E}}$ with $\mathrm{x}_{\mathrm{P}}$ (top right), $\mathrm{E}_{\mathrm{D}}$ (middle left), $\Delta \mathrm{E}_{\mathrm{th}}$ (middle right) and $\mathrm{BU} \mathrm{UOX}$ (bottom right) are represented. The bottom left plot represents the average fraction of plutonium, $<\mathrm{Pu}$ Frac. $>$ versus $\Delta \mathrm{E}_{\mathrm{th}}$. First-order polynomial fitted functions are also represented in blue.

years. This tends to show that the decrease of the power is required to get trajectories that stabilize transuranic elements. Indeed, if the power decreases, the mass of the PWR MOX-EUS is also decreasing. Thus, a smaller plutonium mass is required in the fresh fuel. This is compatible with the decrease of plutonium inventory. In this way, the plutonium incineration is maximized.

Criteria applied to characterize transuranic stabilization can also be used to represent 
Table 5: Statistical parameters of input variable distributions for plutonium and minor actinides stabilization obtained from the FiFo data set.

\begin{tabular}{|l|l|l|l|l|l|}
\hline Variable & $\mathrm{x}_{\mathrm{E}}$ & $\mathrm{x}_{\mathrm{P}}$ & $\mathrm{E}_{\mathrm{D}}$ & $\mathrm{BU} \mathrm{UOX}$ & $\Delta \mathrm{E}_{\mathrm{th}}$ \\
\hline mean & $4.910^{-1}$ & $2.110^{-1}$ & $6.010^{1}$ & $4.710^{1}$ & $3.810^{4}$ \\
\hline std & $5.810^{-2}$ & $1.210^{-1}$ & $1.910^{1}$ & $1.010^{1}$ & $1.110^{4}$ \\
\hline $\min$ & $3.610^{-1}$ & $1.510^{-2}$ & $2.010^{1}$ & $3.010^{1}$ & $2.010^{4}$ \\
\hline $\max$ & $6.510^{-1}$ & $4.610^{-1}$ & $9.910^{1}$ & $6.510^{1}$ & $6.010^{4}$ \\
\hline
\end{tabular}

transuranic elements evolution on the scenario. The figure 14 shows transuranic mass evolution and contributions for plutonium and MA. It is clearly shown that all trajectories are plutonium burner in order to compensate MA production. At the end of the scenario after 100 years of operation, the MA mass is very close to plutonium mass; around 300 tons.

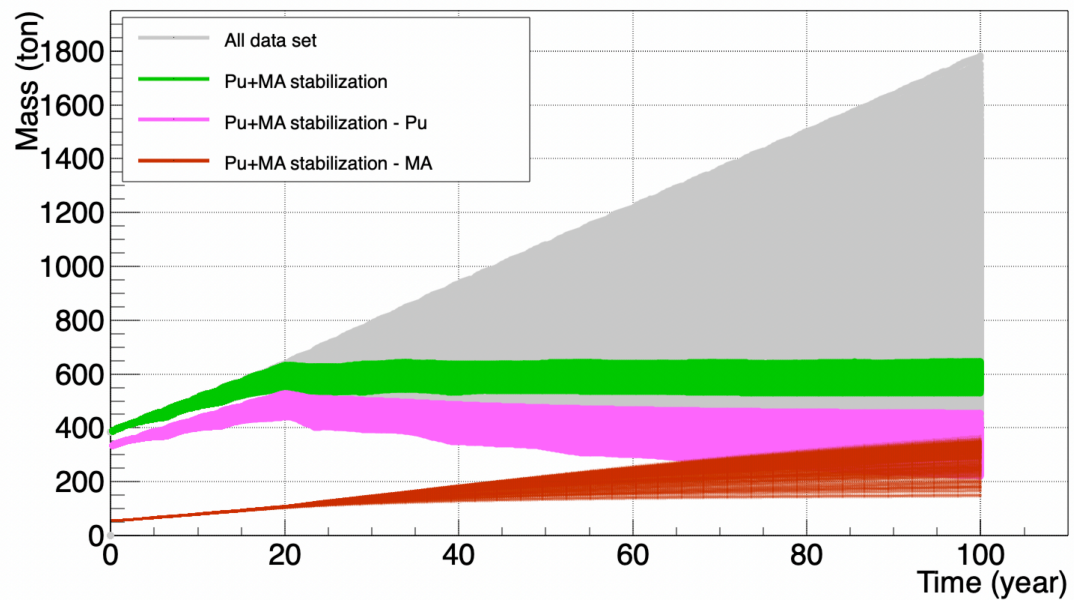

Figure 14: Total transuranic mass evolution in the fleet (gray lines). The green lines represent the sum of plutonium and minor actinides masses for trajectories obtained by stabilization criteria. Purple lines are plutonium mass evolution and red lines are minor actinides mass evolution after the application of the same criteria.

The figure 15 shows trajectories of the data set obtained after transuranic stabilization 
criteria applications.

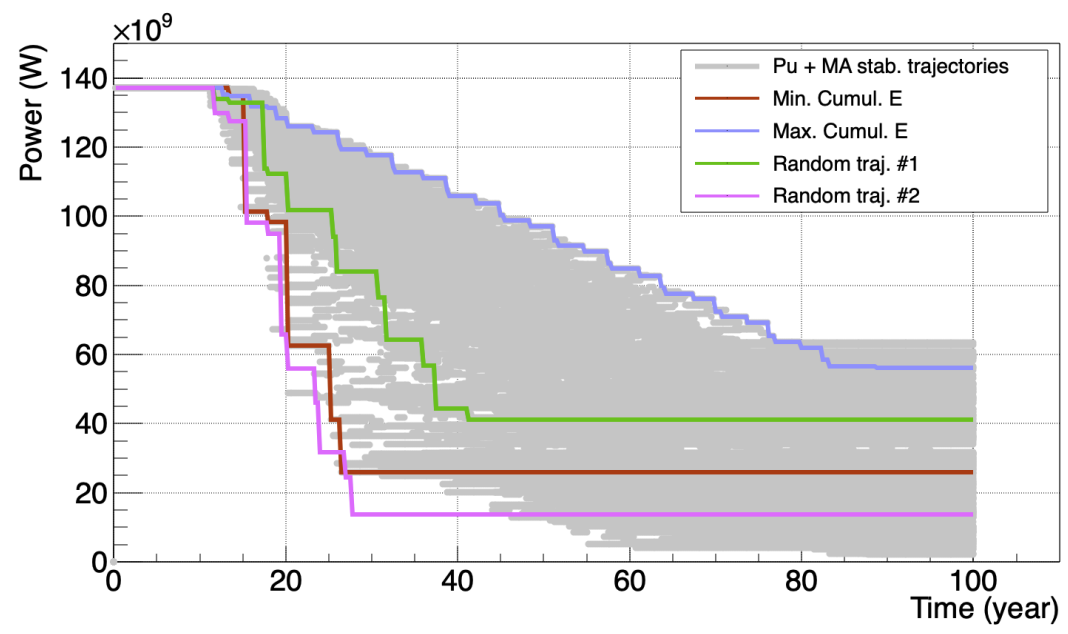

Figure 15: Thermal power evolution for the FiFo data set obtained from the application of plutonium stabilization criteria. Gray lines represent the whole data set. The red line (resp. blue line) is the trajectory that involves the smallest (resp. highest) value of $\Delta \mathrm{E}_{\text {th }}$. Two random examples (green and pink lines) have been added.

In agreement with results obtained before, it is shown that the stabilization of transuranic elements are associated to the decrease of the power. This observation can be explained by the fact that transuranic stabilization involves plutonium consumption. As a consequence, the plutonium availability decreases and the reduction of the power follows. When the fleet is reaching a small thermal power, transuranic elements production and incineration are very small and the sum of plutonium and MA is stable.

\subsection{Transuranic stabilization summary}

Similarly to the plutonium stabilization related section, a condition has been imposed on the plutonium content of PWR MOX-EUS in order to avoid important bias of the input variable $x_{E}$. Application of transuranic stabilization criteria shows that around $50 \%$ of PWR MOX-EUS are required. This value depends on the power evolution of the nuclear fleet. The stabilization is composed of an increase of MA inventory compensated by a decrease of plutonium inventory. A decrease of the nuclear power is necessary in order to fit with plutonium inventory decrease. 
Also, increasing the consumption rate of the plutonium is possible and leads to the decrease of the transuranic inventory. Nevertheless, this involves a higher fraction of PWR MOX-EUS in the fleet and a fast decrease of the nuclear power. The reader can refer to [27] for further details on transuranic decrease feasibility.

\section{Conclusions}

This work aims to study the potential of the plutonium multi-reprocessing in PWRs, in terms of inventory management. The French nuclear fleet has been considered and simulated in order to compose the initial condition of simulation design of experiments.

A context of deep uncertainty characterizes the future of the French electro-nuclear fleet, since the decision on the construction of an SFR demonstrator has been postponed to the end of the 21 st century. In this framework, several options could be examined. If a short-term phase out was considered, there would have no incentive for developing highly innovative technology for plutonium multi-recycling. However, if nuclear energy is planned beyond the medium term and no SFR construction is considered, the plutonium and MA inventory should be controlled, at worst stabilized, at best minimized in the current technology. This is the basic assumption of this work that drives the nuclear fleet evolution possibilities.

The multi-reprocessing of plutonium in PWR is a technical challenge. The plutonium quality decreases with irradiation and safety margins may be strongly affected. As a consequence, innovative assembly designs are required to achieve this goal. In this work, the MOX fuel on enriched uranium support is considered. A design of experiments characterized by wide ranges for reactors technical parameters has been used. This methodology aims to be representative of several possible futures. A high amount of fuel cycle simulations has been performed with the fuel cycle simulator CLASS. A preliminary analysis based on sensitivity indices estimation has shown that the most important input variable that drives the plutonium production is the PWR MOX-EUS fraction in the fleet. The nuclear power evolution is also important. Interactions between input variables are slightly significative.

The analyze of the set of simulations allows highlighting technical conditions re- 
quired to stabilize plutonium and transuranic (plutonium and minor actinides) elements.

We have shown that around $30 \%$ of PWR MOX-EUS are required to stabilize the plutonium inventory on a 100-year scenario. This goal is achievable whatever the nuclear power evolution is. For those scenarios, the multi-reprocessing of plutonium reactor is combined and gathered into a unique reactor by type of fuel in the problem. It is shown in [27] that results obtained from the macro-reactors approach are conserved in a full-size fleet with a high number of standard reactors. Another example, the design of experiment is based on an instantaneous MOX-EUS fueling at the park scale, which 570 is not realistic. Here again, a more complex simulation including several reactors and a progressive MOX-EUS deployment provides similar results [27].

More generally speaking, the impact of the simulation simplifications on results should be precisely investigated. Some international effort, such as the FIT (Functionality Isolation Test) project [36] aims to quantify biases produced by simulation simplifications.

Forthcoming works could go further in safety studies related to multi-reprocessing of plutonium in PWR. In the present work, safety issues related to high plutonium content in the MOX-EUS fuel are taken into account by setting the maximum plutonium content to a value sampled between $8 \%$ and $13 \%$. It has been demonstrated that the conclusions

${ }_{580}$ of this study are non-impacted by this parameter. This approach could be developed in future works by connecting the isotopic composition of the fuel with an estimated 
value of the maximum plutonium content calculated from a full-core simulation. In addition, an essential and required step would be to examine the impact of the plutonium multi-reprocessing on the fuel cycle facilities.

\section{${ }_{585}$ Acknowledgements}

We would like to express our gratitude to the NEEDS program of the Energy Unit of the CNRS (Centre National de la Recherche Scientifique) for the financial support. We also thank Dr Baptiste Mouginot, for his major work as the main developer of the fuel cycle simulator CLASS and Dr Baptiste Leniau for his great work on neutron data 590 predictor implementation. 
[1] Loi du 8 novembre 2019 relative $\tilde{A} a ̆$ l'Âlnergie et au climat, 2019. URL: https://www.vie-publique.fr/loi/ 23814-loi-energie-et-climat-du-8-novembre-2019.

[2] M. Tiphine, C. Coquelet, G. Krivtchik, R. Eschbach, C. Chabert-Koralews, B. Carlier, M. Caron-Charles, G. Senentz, L. Van Den Durpel, C. Garzenne, F. Laugier, Simulations of Progressive Potential Scenarios of Pu Multirecycling in SFR and Associated Phase-out in the French Nuclear Power Fleet, in: GLOBAL 2015 21st International Conference and Exhibition " Nuclear Fuel Cycle for a LowCarbon Future", volume Global 2015 proceedings, Paris, France, 2015. URL: https://hal-cea.archives-ouvertes.fr/cea-02509677.

[3] G. T. Seaborg, J. L. Bloom, Fast breeder reactors, Scientific American 223 (1970) $13-21$.

[4] K. Aoto, P. Dufour, Y. Hongyi, J. P. Glatz, Y. il Kim, Y. Ashurko, R. Hill, N. Uto, A summary of sodium-cooled fast reactor development, Progress in Nuclear Energy 77 (2014) $247-265$.

[5] L. Vautrey, C. P. Zaleski, The fast breeder reactor Rapsodie (1962), Technical Report, France, 1962. URL: https://inis.iaea.org/collection/ NCLCollectionStore/_Public/37/062/37062532.pdf?r=1.

[6] J. Guidez, Phenix - The experience feedback, EDP Sciences, France, 2013.

[7] J. Guidez, G. Prele, Superphenix: technical and scientific achievements, Editions Atlantis Press, France, 2016.

[8] French Safety Authority, The 2006 programme act on the sustainable management of radioactive materials and wastes, 2006. URL: https://www.asn.fr/ annual_report/2010gb/files/waste-law_2010.pdf.

[9] P. coz, J.-F. Sauvage, J.-P. SerpantiÂl', Sodium-Cooled Fast Reactors: the ASTRID Plant Project, Revue GÃlnÃ Arlrale NuclÃlaire (2014) 39-44. 
[10] CEA Nuclear Energy Division, Report on sustainable radioactive waste management, 2012. URL: http: //www . cea.fr/content/download/112863/2133449/file/ CEA-report-sustainable-radioactive-waste-management-18092013. pdf.

[11] G. De Clercq, L. Thomas, D. Goodman, France drops plans to build sodium-cooled nuclear reactor, https://fr. reuters. com/article/idUSKCN1VKOMC, 2019. Reuters news. Accessed: 2020-12-18.

[12] R. Guillaumont, The bataille's law: Scientific research for nuclear wastes in france, L’ActualitÃ̂l' chimique (2005) 8-12.

[13] Thiollière, Nicolas, Clavel, Jean-Baptiste, Courtin, Fanny, Doligez, Xavier, Ernoult, Marc, Issoufou, Zakari, Krivtchik, Guillaume, Leniau, Baptiste, Mouginot, Baptiste, Bidaud, Adrien, David, Sylvain, Lebrin, Victor, Perigois, Carole, Richet, Yann, Somaini, Alice, A methodology for performing sensitivity analysis in dynamic fuel cycle simulation studies applied to a PWR fleet simulated with the class tool, EPJ Nuclear Sci. Technol. 4 (2018) 13.

[14] B. Mouginot, B. Leniau, N. Thiolliere, M. Ernoult, S. David, X. Doligez, A. Bidaud, O. Meplan, R. Montesanto, G. Bellot, J. Clavel, I. Duhamel, E. Letang, J. Miss, Core library for advanced scenario simulation, C.L.A.S.S.: principle \& application, International Conference "The Role of Reactor Physics toward a Sustainable Future" (PHYSOR 2014), 2014. URL: http://hal.in2p3.fr/ in2p3-01119778, poster.

[15] S. Aniel, J. Bergeron, A. Puill, Evaluation of the Maximum Plutonium Content of a MOX-Fuelled Pressurized Water Reactor Versus Isotopic Composition with Respect to the Void Coefficient, IAEATECDOC-941, International Atomic Energy Agency (1997).

[16] NEA, Physics of plutonium recycling : a report by the Working Party on Physics of Plutonium Recycling of the NEA Nuclear Science Committee - Vol. 3, Nuclear Energy Agency, Organisation for Economic Co-operation and Development, 1995. 
[17] NEA, Physics of plutonium recycling : a report by the Working Party on Physics of Plutonium Recycling of the NEA Nuclear Science Committee - Vol. 6, Nuclear Energy Agency, Organisation for Economic Co-operation and Development, 2002.

[18] K. Hesketh, et al., Plutonium Management in the Medium Term, a Review on the OECD/NEA Working Party on the Physics of Plutonium Fuels and Innovative Fuel Cycles (WPPR), 2003.

[19] A. Vasile, P. Dufour, H. Golfier, J. Grouiller, J. Guillet, C. Poinot, G. Youinou, A. Zaetta, Advanced fuels for plutonium management in Pressurized Water Reactors, Journal of Nuclear Materials 319 (2003) 173 - 179. Proceedings of the 8th Inert Matrix Fuel Workshop.

[20] G. Youinou, A. Vasile, Plutonium Multirecycling in Standard PWRs Loaded with Evolutionary Fuels, Nuclear Science and Engineering 151 (2005) 25-45.

[21] Y. Fedorov, B. Bibichev, B. Zilberman, E. Kudryavtsev, Use of recovered uranium and plutonium in thermal reactors, Atomic Energy - AT ENERGY-ENGL TR 99 (2005) 572-576.

[22] A. Pavlovichev, V. Pavlov, Y. Semchenkov, E. Kudryavtsev, Y. Fedorov, B. Bibichev, Neutron-physical characteristics of a vver core with $100 \%$ load of reprocessed uranium and plutonium fuel, Atomic Energy - AT ENERGY-ENGL TR 101 (2006) 863-868.

[23] Bobrov, Evgenii, Alekseev, Pavel, Chibinyaev, Alexander, Teplov, Pavel, Dudnikov, Anatoliy, The choice of the fuel assembly for vver-1000 in a closed fuel cycle based on remix-technology, EPJ Nuclear Sci. Technol. 2 (2016) 42.

[24] O. Méplan, A. Nuttin, O. Laulan, S. David, F. Michel-Sendis, J. Wilson, MURE: MCNP utility for reactor evolution, Description of Methods and First Applications, ENC (2005) 11-14.

[25] T. Goorley, M. James, T. Booth, F. Brown, J. Bull, L. Cox, J. Durkee, J. Elson, M. Fensin, R. Forster, et al., Initial MCNP6 release overview, Nuclear Technology 180 (2012) 298-315. 
[26] F. Courtin, B. Leniau, N. ThiolliÃĺre, B. Mouginot, X. Doligez, A. Somaini, A.A. Zakari-Issoufou, S. David, A. Bidaud, J.-B. Clavel, Neutronic predictors for pwr fuelled with multi-recycled plutonium and applications with the fuel cycle simulation tool class, Progress in Nuclear Energy 100 (2017) 33 - 47.

[27] F. Courtin, Study of plutonium incineration in PWR loaded with MOX on enriched uranium support with the fuel cycle simulator CLASS, Theses, Ecole nationale supérieure Mines-Télécom Atlantique, 2017. URL: https://tel. archives-ouvertes. fr/tel-01668610.

[28] International Atomic Energy Agency (IAEA), The PRIS (Power Reactor Information System) database, https://pris.iaea.org/PRIS/home.aspx, 2020. Accessed: 2020-12-18.

[29] International Atomic Energy Agency (IAEA), Country nuclear power profiles : France, 2020. URL: https://cnpp.iaea.org/countryprofiles/France/ France.htm.

[30] G. Martin, M. Guyot, F. Laugier, G. Senentz, G. Krivtchik, B. Carlier, D. Lecarpentier, F. Descamps, C. Chabert, R. Eschbach, FRENCH SCENARIOS TOWARD FAST PLUTONIUM MULTI-RECYCLING IN PWR, in: ICAPP, Charlotte, United States, 2018. URL: https://hal-cea . archives-ouvertes . fr/ cea-01908271.

[31] G. Pujol, B. Iooss, A. J. with contributions from Khalid Boumhaout, S. D. Veiga, T. Delage, J. Fruth, L. Gilquin, J. Guillaume, L. Le Gratiet, P. Lemaitre, B. L. Nelson, F. Monari, R. Oomen, B. Ramos, O. Roustant, E. Song, J. Staum, T. Touati, F. Weber, sensitivity: Global Sensitivity Analysis of Model Outputs, 2017. URL: https://CRAN.R-project.org/package=sensitivity, r package version 1.14.0.

[32] R Development Core Team, R: A Language and Environment for Statistical Computing, R Foundation for Statistical Computing, Vienna, Austria, 2008. URL: http://www.R-project. org, ISBN 3-900051-07-0. 
[33] H. Monod, C. Naud, D. Makowski, Uncertainty and sensitivity analysis for crop models, Working with dynamic crop models: Evaluation, analysis, parameterization, and applications 4 (2006) 55-100.

[34] A. Janon, T. Klein, A. Lagnoux, M. Nodet, C. Prieur, Asymptotic normality and efficiency of two sobol index estimators, ESAIM: Probability and Statistics 18 (2014) 342-364.

[35] R. Brun, F. Rademakers, ROOTâĂ ̌an object oriented data analysis framework, Nuclear Instruments and Methods in Physics Research Section A: Accelerators, Spectrometers, Detectors and Associated Equipment 389 (1997) 81-86.

[36] N. Thiollière, FIT (Functionality Isolation Test) Project, first results, in: Technical Workshop on Fuel Cycle Simulations, Urbana Champaign, United States, 2019. URL: https://hal . archives-ouvertes .fr/hal-02461994. 